\title{
Rabaska
}

Revue d'ethnologie de l'Amérique française

PICHETTE, JEAN-PIERRE (sous la direction de), avec la collaboration de NANCY-GAËLLE BARRAS, OLGA BEAULIEU, DIANE BRADETTE. Passeur de mémoire en Ontario français. Germain Lemieux, s.j., / French Tradition Lives On in Ontario. Germain Lemieux, s.j. Sudbury, Centre franco-ontarien de folklore, 2001, 50 p. + 50 p. Illustrations. ISBN 2-9803432-2-6

\section{Yvette Gaudet}

\section{Volume 3, 2005}

URI : https://id.erudit.org/iderudit/201732ar

DOI : https://doi.org/10.7202/201732ar

Aller au sommaire du numéro

\section{Éditeur(s)}

Société québécoise d'ethnologie

ISSN

1703-7433 (imprimé)

1916-7350 (numérique)

Découvrir la revue

Citer ce compte rendu

Gaudet, Y. (2005). Compte rendu de [PICHETTE, JEAN-PIERRE (sous la direction de), avec la collaboration de NANCY-GAËLLE BARRAS, OLGA BEAULIEU, DIANE BRADETTE. Passeur de mémoire en Ontario français. Germain Lemieux, s.j., / French Tradition Lives On in Ontario. Germain Lemieux, s.j. Sudbury, Centre franco-ontarien de folklore, 2001, 50 p. +50 p. Illustrations. ISBN 2-9803432-2-6]. Rabaska, 3, 160-161. https://doi.org/10.7202/201732ar d'utilisation que vous pouvez consulter en ligne. 
Pichette, Jean-Pierre (sous la direction de), avec la collaboration de NancyGaëlle Barras, Olga Beaulieu, Diane Bradette. Passeur de mémoire en Ontario français. Germain Lemieux, s.j., / French Tradition Lives On in Ontario. Germain Lemieux, s.j. Sudbury, Centre franco-ontarien de folklore, 2001,50 p. +50 p. Illustrations. ISBN 2-9803432-2-6.

En 1998, le Centre franco-ontarien de folklore célébrait le cinquantième 
anniversaire de la carrière de Germain Lemieux. Grâce au travail admirable de ce folkloriste, un patrimoine oral de trois mille chansons et de six cents cinquante contes avait été sauvegardé. Pour commémorer ce demi-siècle de succès en Ontario français, on créa une exposition intitulée "Passeur de mémoire depuis cinquante ans, 1948-1998, Germain Lemieux, s.j. ». La réaction immédiate et enthousiaste du public incita le Centre à garder une trace indélébile de cet événement. C'est ainsi que fut conçu le présent catalogue qu'on peut lire dans les deux langues officielles en présentation tête-bêche.

Sous le thème du « passeur de mémoire », qui illustre bien le travail de l'ethnologue, l'équipe de rédaction a réparti le scénario en six rubriques. "Le passeur, son passé, sa passion " fait voir la formation et la vocation du jésuite pédagogue. Avec « Maîtres-passeurs et rites de passages », on voit apparaître les grands pionniers de l'ethnologie, Marius Barbeau, Félix-Antoine Savard et Luc Lacourcière, qui ont exercé une influence directe sur la carrière de Germain Lemieux. L'aspect technique de la recherche du folkloriste est examiné dans un troisième volet " Aide-mémoire et instruments du passeur ». Puis le lecteur a droit à d'excellentes photos représentant quelques informateurs interrogés dans les régions du Canada français à la section " Mémoires passeuses, passagères, passées ». Ensuite, Lemieux montre son émerveillement face à l'adresse de quelques chanteurs dans « Passages ». Le dernier chapitre, "Passation ", contient des exemples d'artistes qui transforment par leurs œuvres les travaux de Lemieux. Le catalogue s'achève sur de courts hommages à Lemieux, le grand passeur de mémoire de l'Ontario français.

Rédigé dans un style qui permet de bien représenter la matière de l'exposition, ce cahier est illustré de photos anciennes, de quelques œuvres artistiques (telles les sculptures de Lemieux). Tous les textes du livre sont extraits d'entrevues, ce qui donne l'impression au lecteur que c'est Germain Lemieux lui-même qui les guide dans cette exposition. De courtes chronologies, des rubriques explicatives et quelques symboles agrémentent ce document. Il en résulte un livret attrayant, clair et facile à suivre. Ce catalogue s'avère une excellente introduction à l'œuvre du folkloriste et au travail de l'ethnologue il y a cinquante ans. Il rend bien justice à la matière de l'exposition, dont on ne semble perdre ni la couleur ni la saveur.

Yvetre GaudeT

Université Sainte-Anne, Pointe-de-l'Église 